\title{
PRESSURE DROP WITH FORCED-CONVECTION BOILING OF POTASSIUM
}

R. P. Wichner and H. W. Hoffman

Reactor Division

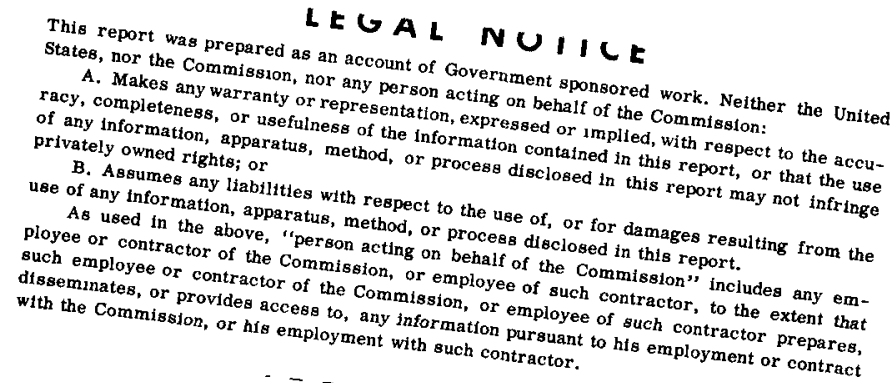

For presentation at the Fourth High-Temperature Liquid-Metal Fisat Transfer Technology Conference to be held September 28-29, 1965, at Argonne National Laboratory, Argonne, Illinois

OAK RIDGE NATIONAI IABORATORY

Oak Ridge, Tennessee

Operated by

UNION CARBIDE CORPORATION

for the

U. S, ATOMIC ENERGY COMMISSION 


\section{DISCLAIMER}

This report was prepared as an account of work sponsored by an agency of the United States Government. Neither the United States Government nor any agency Thereof, nor any of their employees, makes any warranty, express or implied, or assumes any legal liability or responsibility for the accuracy, completeness, or usefulness of any information, apparatus, product, or process disclosed, or represents that its use would not infringe privately owned rights. Reference herein to any specific commercial product, process, or service by trade name, trademark, manufacturer, or otherwise does not necessarily constitute or imply its endorsement, recommendation, or favoring by the United States Government or any agency thereof. The views and opinions of authors expressed herein do not necessarily state or reflect those of the United States Government or any agency thereof. 


\section{DISCLAIMER}

Portions of this document may be illegible in electronic image products. Images are produced from the best available original document. 
YESSURE DROP WITH FORCED-CONVECTION BOILING OF POTASSTUM ${ }^{*}$

\author{
R. P. Wichnel and H. W. Hoffman \\ Dak Ridge IVational Laboratory \\ Oak Ridge, Tennessee
}

\begin{abstract}
The results are given for the pressure drop with boiling potassium in forced-convection flow through a vertical, circular tube. The data, which comprise a single series of measurements (Series D), were obtained in a 6-ft long $\times 0.270-$ in.-ID tube having pressure taps at l-ft spacings over the final $4 \mathrm{ft}$ of the channel. The pressuremeasurement system and its deficiencies are discussed; the primary difficulty appears to be "aging" of the diaphragms in the pressure transmitters over long exposure times at high temperatures. The pressure distribution along the boiler was estimated using both homogeneous and Lockhart-Martinelli descriptions of the flow; the calculated exit pressures compared favorably with the measured values.
\end{abstract}

* Research sponsored by the U. S. Atomic Energy Commission under contract with the Union Carbide Corporation. 


\section{INTRODUCTION}

The pressure drop associated with forced-convection boiling is of significant concern in the design of power systems utilizing this mode of cooling and has been the subject of intensive study. Most attention has focused on water in a variety of geometries at high system pressures. More recently, interests have broadened to include lower pressure systems (including subatmospheric) and other coolants (such as the alkali liquid metals).

While we have been accumulating pressure-drop data in the course of our heat-transfer studies with boiling potassium in upward forced flow through vertical circular tubes, we have described our results only briefly at these conferences. ${ }^{1}$ The discussion which follows considers some of the difficulties we have encountered in making these measurements and gives a preliminary analysis of the daca.

\section{EXPERIMENTAL APPARATUS}

The test channels utilized in our initial studies with boiling potassium provided only limited information on the pressure drop. Thus, both the "lowflux" and "high-flux" boilers" were designed with pressure taps at the inlet and exit orly. As a consequence, the resulting data ${ }^{1,3}$ included losses (of unknown magnitude) associated with flow through an inlet mixing chamber, around exit-end thermowells, and through contractions and expansions at the exit.

An advanced design of the "high-flux" boiler, incorporating an additional pressure tap at the midpoint, was abandoned because of fabrication difficulties; and a test unit of intermediate-flux capability was constructed and installed. This new boiler was designed to provide data on both the heat transfer and the pressure drop; a schematic representation is shown in Fig. 1. The boiler was machined from a 7-ft length of $1 / 2$-in. double extra heavy IPS type 347 stainless steel pipe (0.270-in. inside diameter, 0.839-in. outside diameter). As shown in Fig. 1, the boiler was divided into six 12-in.-long sections which were heated radiantly by individual clamshell heaters of 1 1/4-in. inside diameter. The heated portions were separated by 1 1/2-in.-Iong gaps in which the wall was 


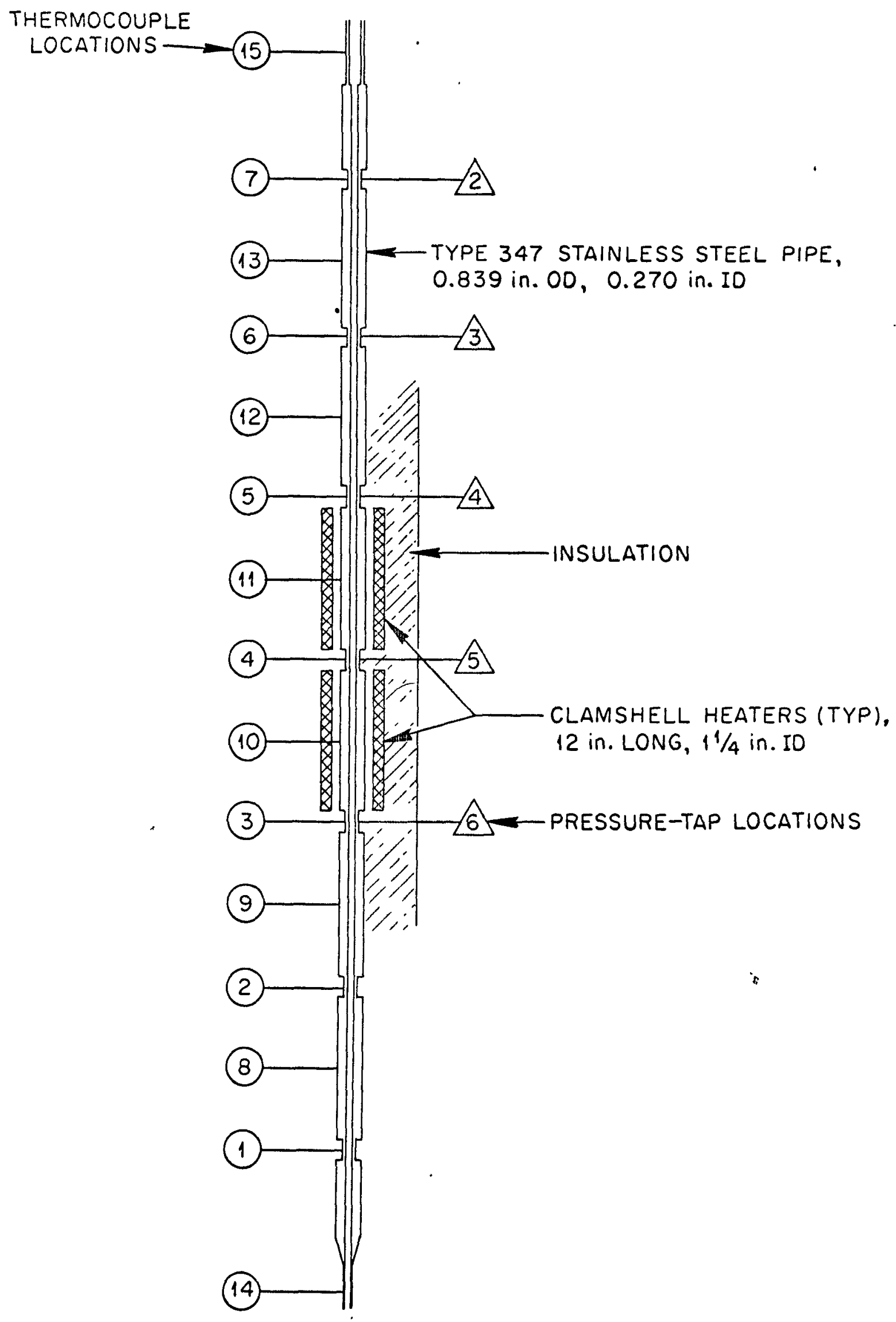

Fig. 1. Schematic of Medium-Flux Boiler Section. 
thinned from the original $0.285 \mathrm{in}$. to 0.075 in. Pressure taps (see Fig. 2 for corstruction detail) were located in the final four gaps and at the boiler exit. The pressures at positions 2, 3, 5, and 6 were measured with Taylor diaphragm-type pressure transmitters having NaK-filled lines and strain-gage signal converters; at position 4, the pressure was determined with a 6-in. bronze Bourdon-tube gage maintained at the calibration temperature of $I 60^{\circ} \mathrm{F}$. Care was taken to insure that the pressure-tap lines leaving the boiler were horizontal and liquid filled. While cooling jackets were provided on all pressure taps, it was found in practice that the normal heat loss was sufficient to assure the absence of vapor in the lines.

A pair of 0.008-in.-diam Pt-Pt 10\% Rh thermocouples were also welded to the tube wall in each of the interheater gaps; the leads of these thermocouples were brought out along the pressure-transmitting lines. Fiberfrax insulation in these regions created an essentially adiabatic zone. In addition, tube-wall temperatures were obtained at the midpoint of each heated section by Pt-Pt $10 \% \mathrm{Rh}$ couples placed in 0.035 -in.-diam holes drilled radially into the tube wall; the locations of the bottoms of these wells with respect to the inside tube surface are indicated in Fig. 2. The 8-miI thermocouple wires were threaded through two-hole ceramic insulators $(0.031-i n$. outside diameter) and individually resistance welded to the stainless steel at the bottom of the well. The inside surface temperature was obtained by extrapolation from the temperatures measured at the bottom of the thermocouple wells.

The pressure-measuring system was calibrated at $1000^{\circ} \mathrm{F}$ over the range 4 to 25 psia by comparison with a precision test gage. During calibration, the liquid potassium was held in the sump tank; and the system was filled with helium. Calibration was effected both before and after each run series. In addition, the electrical part of the system was checked periodically by detaching the straingage leads and imposing a standard millivolt signal at this point.

The Taylor devices installed on this loop were found to be unstable, exhibiting significant changes in calibration over a period of time. For example, the output of one transmitter varied over a six-month period by nearly $12 \%$. These changes were always in a positive direction and derive possibly from "aging" of the diaphragms due to prolonged exposure at high temperatures, 


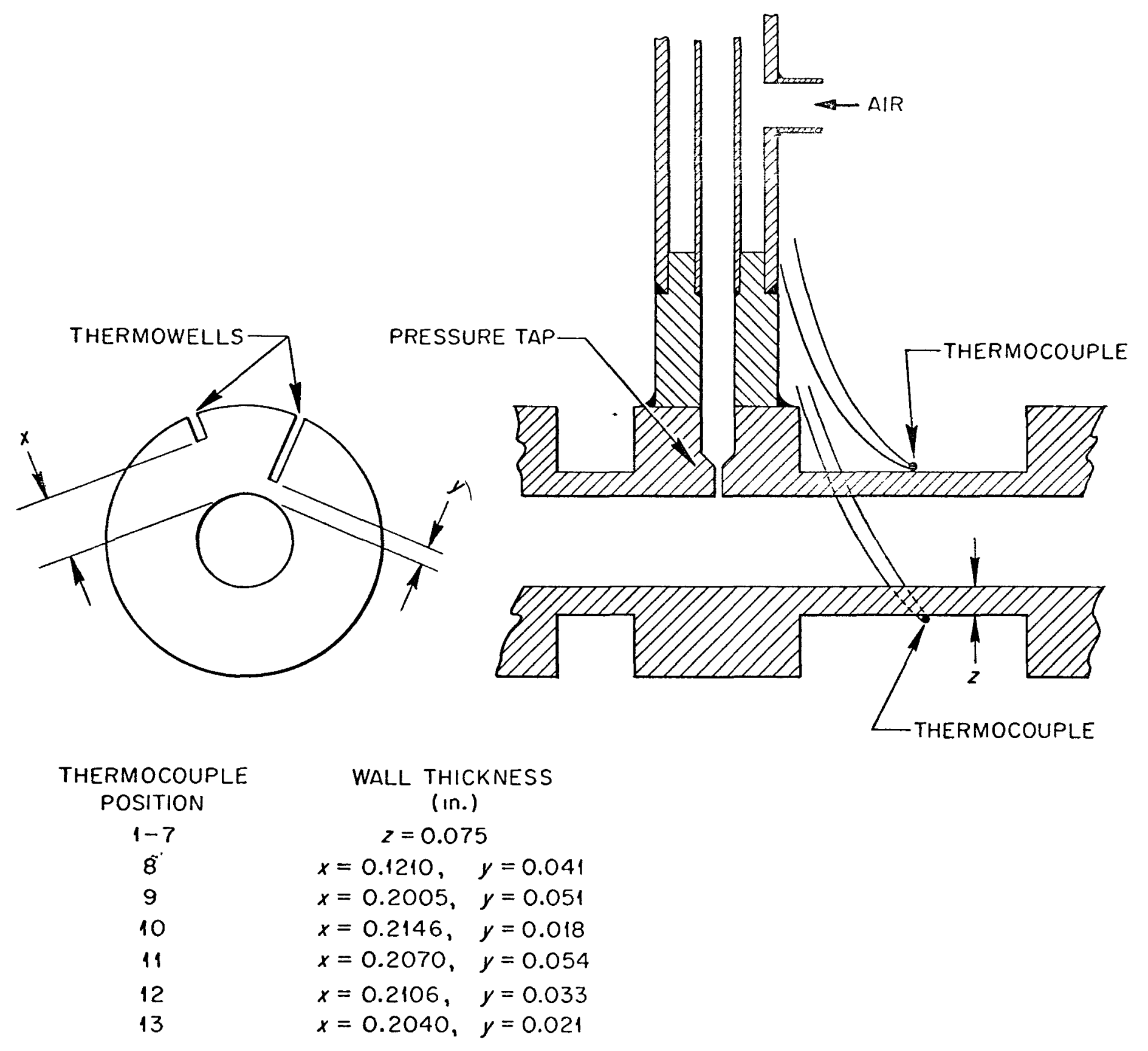

Fig. 2. Thermocouple and Pressure Tap Details of Medium-Flux Boiler. 
occasional imposition (as during calibration) of subatmospheric pressures, and/or corrosion in the potassium environnent. While this factor does introduce some uncertainty in the final results, the major effect has been annoyance rather than loss of precision.

The quality at the boiler exit was determined by passing the effluent vapor-liquid mixture through a separator and measuring the flow rates of the resulting vapor (after condensation) and liquid streams both volumetrically in calibrated hold tanks and dynamically by electromagnetic flow meters. other features of the experimental system have been described previously, ${ }^{1}, 3$

\section{EXPERTMENTAL AND CALCULATED RESUITS}

The data obtained in the Series $D$ experiments for the axial pressure distrilnt, in with boiling potassium flowing through a vertical, circular tube are sis 1 ized in Table 1 along with the inlet mass flow, exit quality, and heat inlp.ll. Results for two typical runs are shown graphically in Figs. 3 and 4. in the first of these (Rurn-D-4, Fig. 3), a low mass flow-high exit quality cundition existed; while in the second (Run D-15, Fig. 4), the situation was reversed. Both figures present measured and predicted pressures, fluid temperatures, and calculated qualities as a function of distance from the boils: inlet; the locations of the six boiler heaters are also indicated.

The quality variation along the boiler was calculated from an energy balance which neglected the wall friction and the static head but retained the kinetic energy term. A trial-and-error solution was then effected in which who nagitude of the slip ratio was systematically adjusted to generate an exic jality agreeing as closely as possible with the measured value; a zero inlet, quality was assumed. The results are shown by the open circles in the lower portion of Figs. 3 and 4 ; the measured exit qualities are given by the filled circles. Significant changes in the slip ratio were found to have only minor effects on the calculated exit quality. This result is not surprising in that for the conditions of this experiment the enthalpy term dominates the kinetic energy term in the energy balance. As observed for the 


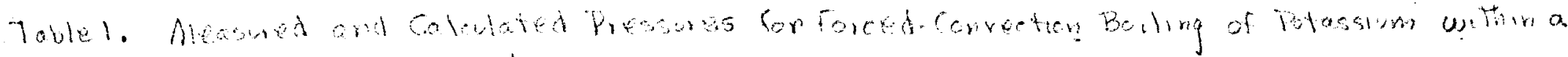
Vertical Crevlar Ghannel.

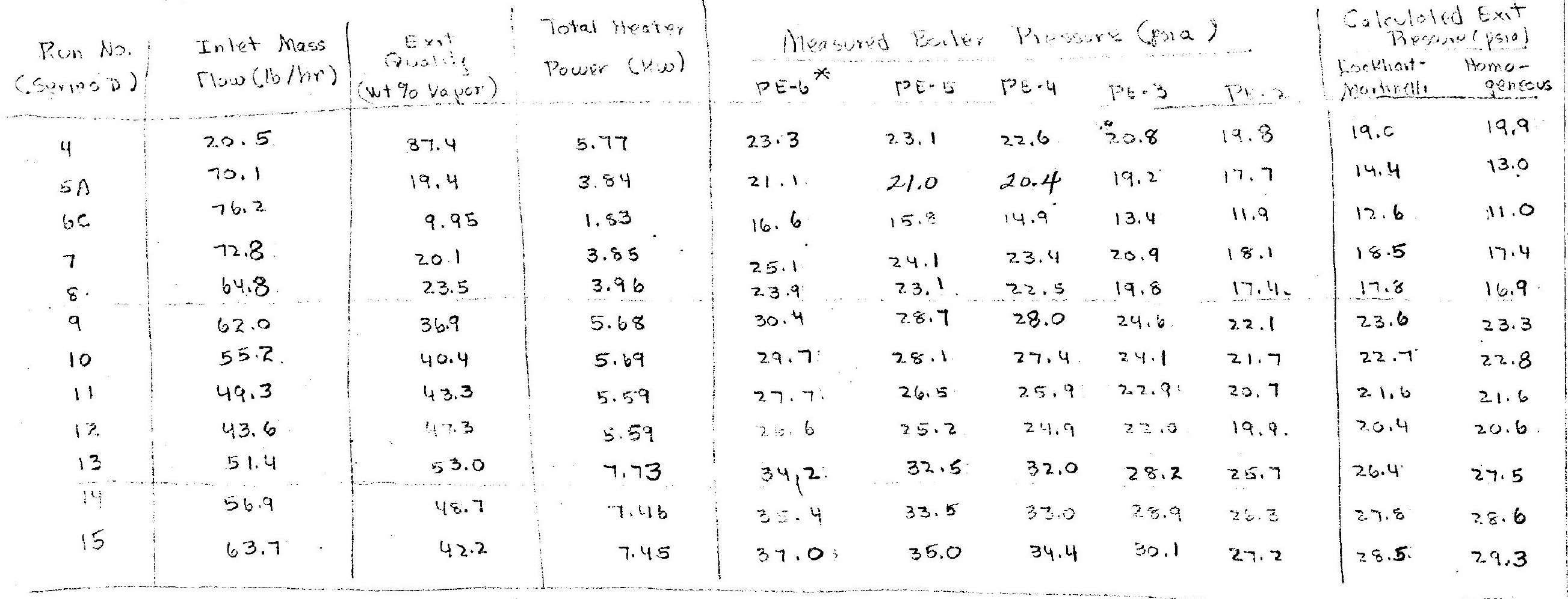

* Pressure tap locations, listaners measured from boler iniet:

PE-6, 2.156.5t; PE-5, 3.2345t; PE.4, 4.313ft; PE-3, 5.3215t; PE-2,6.4675t. 


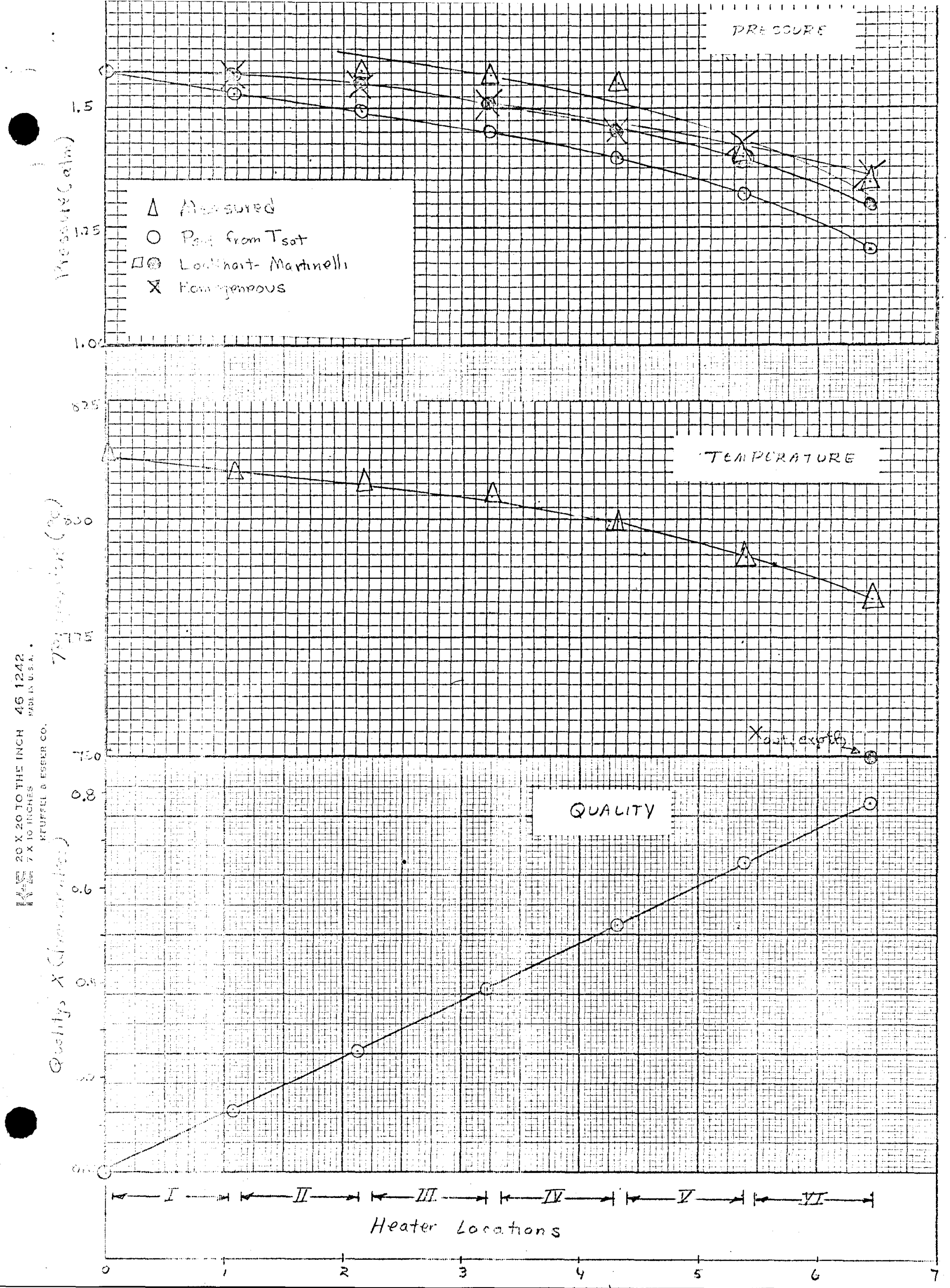


strter

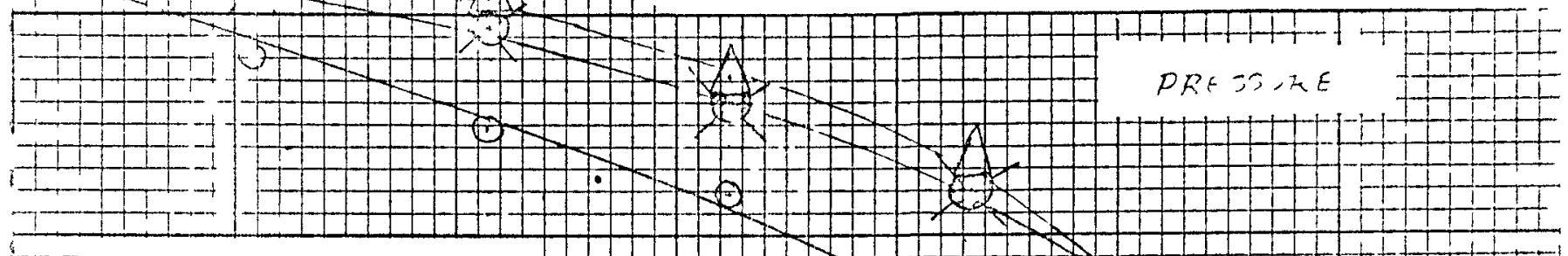

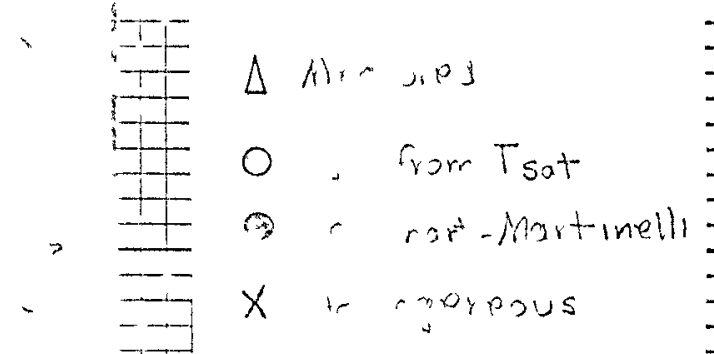

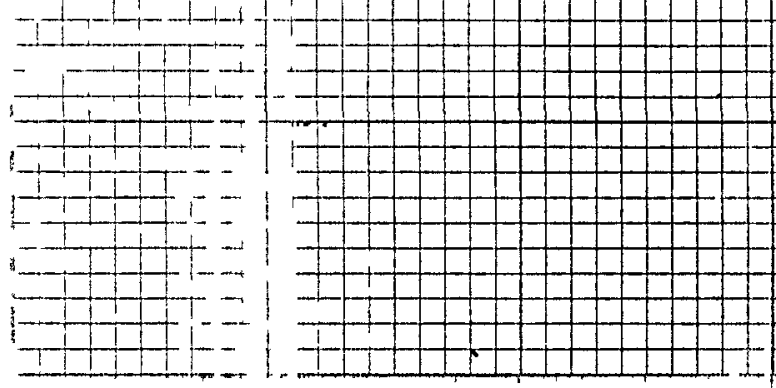

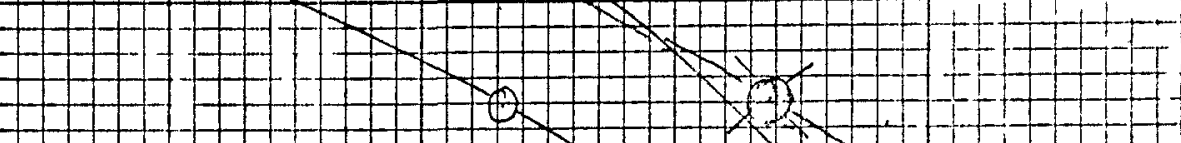

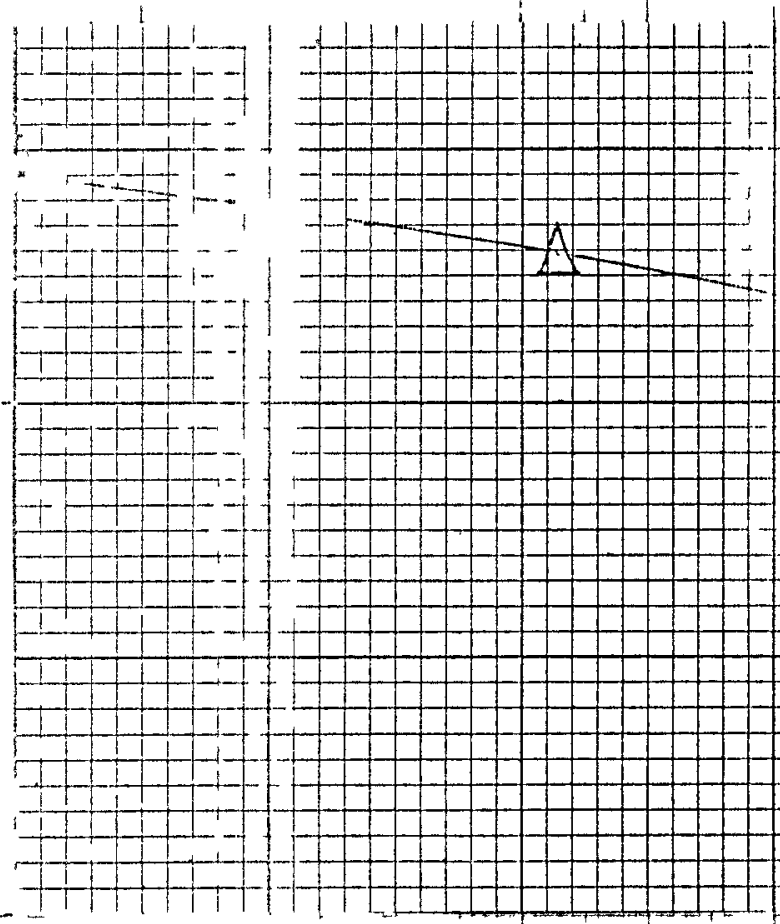

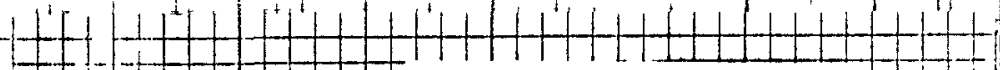

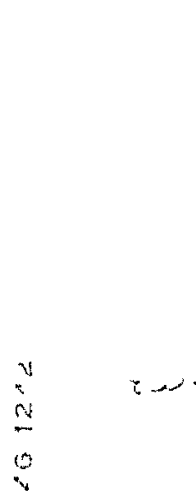

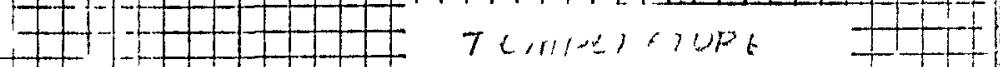

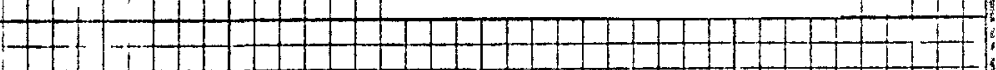

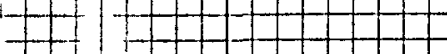

At $+1+7$ $+2+1$

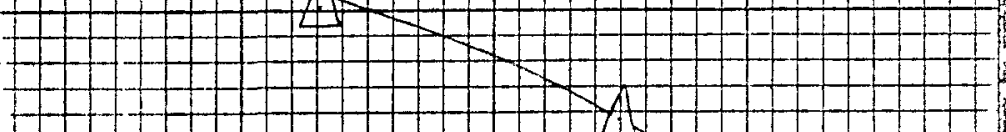

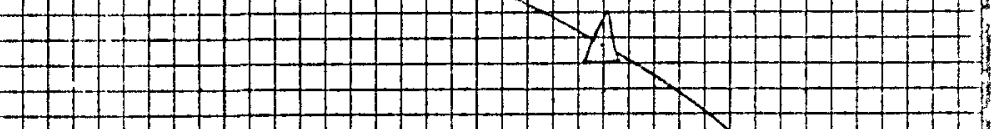

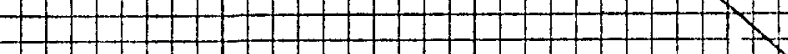

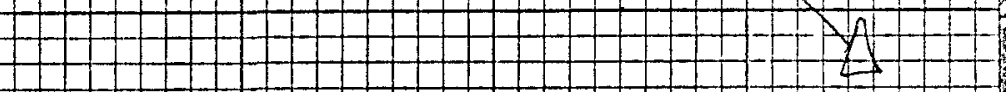
-

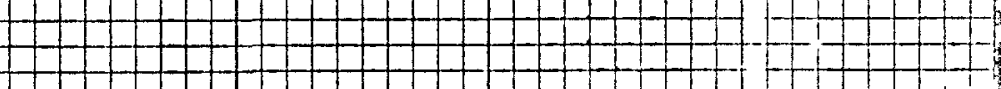

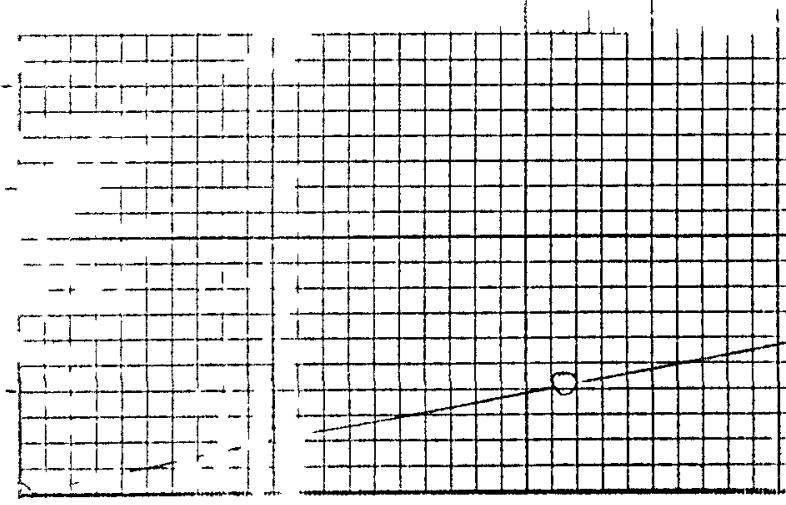

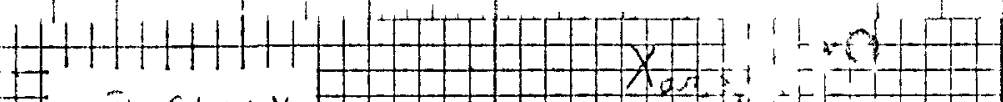

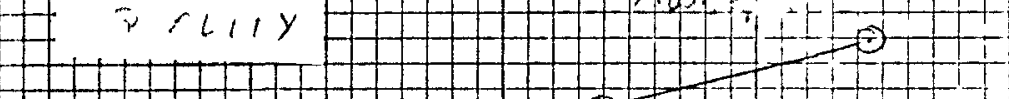
$57+00+1+2$ 
two cas 35 , raphed, the calculated exit quality is always somewhat lower than the messu, d exit quality. Since the slope of the axial quality profile is fixed by the known heat input, the inlet quality could be obtained by extrapolation kack from the measured value. The inlet qualities thus obtained were $15 \%$ for jun D-4 and 10\% for Run D-15. These estimated values are markedly greater. thin the qualities belirvil, on a qualitative basis, to have existed at the $b$ ' er inlet and may refl. $l$ in jurt errors (on the high side) in the measurf 0 alities due to vaporiation howween the boiler exit and the measuremert : rition. In any event, the pressure-drop estimations discussed below were basi a on the calculated qualities without adjustment for the indicated deviatio' From the measured exit quality.

The cuntral portion of both Figs. 3 and 4 show the fluid temperature distribution along the boiler. The data plotted are wall temperatures measured in the thin-walled ( $0.075 \mathrm{in.})$, adiabatic zones ( $1.5 \mathrm{in}$. long) between the heaters. It is presumed, under these circumstances, that the wall temperature is essentially the same as the fluid temperature.

Pressures measured at five positions along the boiler are shown by the open triangles in the upper portion of Figs. 3 and 4; as noted in Fig. 1, the first pressure tap (PE-6) was located in the adiabatic zone between the second and third heaters. The data show somewhat more scatter than previously observed in run Series $\mathrm{C}^{\mathbf{4}}$ this may result from the uncertainties associated with the pressure-measurement system as discussed above in the section on apparatus. An arbitrary smooth curve has been drawn through the data.

The lower pressure curve in both Pigures gives the saturation pressure (open civles) as derived from the fluid temperature data. The pressure distribut on thus derived shows a trend with distance along the boiler that agrees ch sely with the curve through the measured values but falls significantly alu consistently below the latter. This discrepancy in magnitude results in part, erom the use of the vapor pressure correlation of Iemon et al. ${ }^{5}$ in this analysis; at a given $\mathrm{T}_{\text {sat }}$, Lemmon and his co-workers found $\mathrm{P}_{\text {sat }}$ to be less than the value indicated by other avajlable correlations. Thus, using the equation developed by Ewing et al., ${ }^{6}$ the saturation pressure calculated at position PE-4 
in Run $\mathrm{D}-4$ is 1.47 atm; this compares with a value of 1.39 atm calculated from the Iermon et al. equation and 1.54 atm measured. Similarly, for Run D-15 at the same measurement station, $P_{\text {sat }}=2.14 \mathrm{~atm}$ according to Lemmon, 2.22 atm according to Ewing, and $2.34 \mathrm{~atm}$ measured. The remaining difference between the measured pressure and that calculated from $T_{\text {sat }}$ could derive from low temperature readings due to heat loss in the "adiabatic" zone or from a systemic error in the pressure measurements.

For purposes of comparison, the pressure drop along the boiler was also estimated using both the homogeneous and the Lockhart-Martinelli $i^{7}$ models for the flow. Thus, the filled triangles in Figs. 3 and 4 show the results obtained by assuming the fluid to be homogeneous, while the closed circles give corresponding values obtained by the Lockhart-Martinelli procedure with corrections for changes in the kinetic and gravity heads.

The Blasius friction-factor equation, $f_{B}=0.0396 \mathrm{~N}_{\mathrm{Re}}^{-0.25}$, was used in the homogeneous calculations; while, the analogy relation, $f_{B}=0.023 \mathrm{~N}_{\mathrm{Re}}^{-0.20}$, was used in the Lockhart-Martinelli computation. The following further comments are pertinent to the estimation of the pressure drop by the LockhartMartinelili procedure:

]. Since the slip ratio was unknown, a val ue of unity was assumed in the calculations of the kinetic and gravity head corrections.

2. For convenience in the computer calculations, an empirical equation was fitted to the Lockhart-Martinelli parameters; thus,

$$
\ln \phi_{d i t}=1.478-0.5403 \ln x_{t t}+0.05194\left(\ln x_{t t}\right)^{2}+0.000698\left(\ln x_{t t}\right)^{3},
$$

where $b_{2: 1}$, is the square root of the ratio of the total two-phase pressure drop, $(\mathrm{dP} / \mathrm{dL})_{\mathrm{m} T \mathrm{~T}}$, to the pressure drop for the liquid phase only, $(\mathrm{aP} / \mathrm{dL})_{\ell}$; and

$$
x_{t t}=\left(\frac{1}{x}-1\right)^{0.9}\left(\frac{\mu_{l}}{\mu_{v}}\right)^{0.1}\left(\frac{\rho_{v}}{\rho_{l}}\right)^{0.5},
$$

$x$ beinc; : mean quality in eacl lleatci section. Over the range of the experimente.l i. $i, 0.01<X_{t t}<1.00$, $111 \mathrm{is}$ eminical equation overestimates $\phi_{\text {ltt }}$; at $X_{t t}=\ldots$, , the error is $\sim 5 \%$, and at $x_{t t}=0.01, \sim 10 \%$. 
3. Since the pressure was not measured at the boiler inlet, the starting point for the pressure calculations was assumed to be $\mathrm{P}_{\text {sat }}$ as estimated from the wall temperature measurements. This is probably not an unreasonable assumption in that the fairly long loop section immediately preceding the boiler is essentillily adiabatic; and, hence, the wall temperature measured at the end of this rion should equal the fluid temperature. The data shown in Figs. 3 and 4 suggest this conclusion.

\section{TISCUSSION}

In ' i"w of the error discus'li above in the evaluation of $\phi_{\text {ltt }}$, the Serie: I "ta have not been prest, led in "he usual graphical form of the pressur $=$. op ratio versus the Inckhart-Martinelli parameter, $x_{t t}$. These calculaticis will be repeated in the near future using a newer, more precise computer procedure for evaluating $\phi_{\text {ltt }}$. Thus, any comparison of the present data witl results obtained with water under similar experimental conditions must be deierred.

The final three columns of Tabile I provide a comparison of measured and calculated exit pressures; in general, the agreement between the tabulated values is good. However, there does not appear to be any consistent trend in these comparisons. Thus, for Run D-4, Lockhart-Martinelli predicts an exit pressure less than measured, while the homogeneous model yields a value greater than measured. In Run D-8, the situation is reversed; while in Run D-15, both calculations indicate exit pressures greater than measured. As discussed above, these comments must be qualified somewhat in respect to the LockhartMartinelli calculation. An overestimate in the pressure drop by $15 \%$ on the average is indicated; this results in predicted exit pressure which are 3 to $5 \%$ low.

\section{ACKNOWLEDGMENTS}

Tile a uthors acknowledge the contributions of A. I. Krakoviak in the design and cowtuction of the test section, of R. D. Bundy and B. J. Sutton in obtaining the wries $D$ experimental datid, and of Dolores Eden for her conscientious typing of the manuscript. 
REFERENCES

1. H. W. Hoffman, "Recent Experimental Results in ORNL Studies with Boiling Potassium," pp. 334-350, Proceedings of 1963 High-Temperature LiquidMetal. Heat Transfer Technology Meeting, Vol. I, USAEC Report ORNL-3605, Oak Ridge National Iaboratory, November 1964.

2. H. Wr. Ioffman and A. I. Krakoviak, "Convective Boiling with Liquid Potas-. sium," pp. 19-37, Proceedings of the 1964 Heat Transfer and Fluid Mechanics Inst: $=$ ute, W. H. Gredt and S. Levy, editors, Stanford University Press, Stanfurd, California, 1964.

3. A. I. rrakoviak and H. W. Hoffman, "Boiling Potassium Heat Transfer: Forcei-Convection System," pp. 19-20, Studies in Heat Transfer and Fluid Mecknincs, Progress Report for Period January 1 - September 30, 1963, H. W. Hoffman and J. J. Keyes, Jr., editors, USAEC Report ORNL-TM-915, Oak Ridge Naticnal Laboratory, October 1964.

4. A. I. Krakoviak and H. W. Hoffman, "Boiling Potassium Heat Transfer: Forced-Convection System," pp. 7, 12-15, Studies in Heat Transfer and Fluid ivchanics, Progress Report for Period October 1, 1963 - June 30, 1964 , H. W. Hoffman and J. J. Keyes, Jr., editors, USAEC Report ORNL-TM-II48, Oak Ridge National Laboratory, August 1965.

5. A. W. Lemmon et al., "The Thernodynamic and Transport Properties of Potassium," pp. 88-115, Proceedings of 1963 High-Temperature Liquid-Metal Heat Transfer Technology Meeting, Vol. I, USAEC Report ORNL-3605, Oak Ridge National Laboratory, November 1964.

6. C. T. Ewing et al., "High Temperature Properties of Sodium and Potassium, l2th Progress Report for Period 1 July to 30 September 1963," U. S. Naval Research Laboratory Report NRL-6094, June 1964.

7. R. W. Lockhart and R. C. Martinelli, "Prediction of Pressure Drop, for Isothermal Two-Phase, Two-Component Flow in Pipes," Chem. Eng. Progr., 45: 39 (1949). 